\title{
Prediction and Analysis of Society's Networks
}

\author{
Xin Wang1, Xinshe Qi1, Na Wang1, Na Qu ${ }^{2}$ \\ ${ }^{1}$ College of Information and Communication, National University of Defense Technology, Xi'an, China \\ ${ }^{2}$ Rocket Ngineering University, Xi'an, China \\ Email:39652970@qq.com
}

How to cite this paper: Wang, X., Qi, X.S., Wang, N. and Qu, N. (2018) Prediction and Analysis of Society's Networks. Journal of Applied Mathematics and Physics, 6, 290-295. https://doi.org/10.4236/jamp.2018.61027

Received: December 27, 2017

Accepted: January 28, 2018

Published: January 31, 2018

\begin{abstract}
According to the information theory model, I use the qualitative analysis to explain the information flows through the media channel become news. Besides, I make use of a pyramid model to expound the relationship among each media. I combine the information theory model into the prediction process, taking advantage of curve fitting and listing out different ratios of media capacities. Finally I get the small relative error between the fitting result and the reality. Based on the ELM model, I classify the information in two ways on the basis of the four specific factors. By taking the influence degree of public opinion into account, I quantify the factors with different ratios to determine how they could be used in information spreading.
\end{abstract}

\section{Keywords}

Edge Route, Topology, Society's Network

\section{Introduction}

Nowadays, smartphones shrink the world a lot. With the development of the technology, people get more chances to obtain the information. It also brings numerous annoyances to people at the same time. The world is really eager to know about whether the information that communication network provided is what they really need. Due to the important role that the society's networks play in the information spreading, mining the evolution of the methodology, purpose, and functionality of society's networks is needed.

However, the value of information spreading such quickly by varies of media hasn't drawn the people's attention. Thus, people cannot recognize the value of information. So we try to analyze the relationship between speed flow of information and inherent value of information in this paper. 


\section{Description and Analysis}

Generally, information was firstly spread by oral form, and then by the written form. After a long distance spreading, it might not be "news" in the sense. Assume that, if a piece of information traveled around the world at ancient times (For instance, before 16th century), it would be no longer a piece of "news".

Meanwhile, newspapers and other media can also be regarded as a record. In that sense, news has been published in public places so that anyone who is interested in it could come to see it.

Based on the theory of information, we can figure out that information can be divided into 3 parts, they are: real information, prior information and news [1]. So we develop a basic model to explore the flow of information.

\subsection{Comparison between Prediction and Reality}

We can get today's reality through the Internet. To compare these with the predict ones we got in table, we can make a quantitative comparison. The specific numerical values are listed as follows.

Table 1 shows difference between the predicted values and reality of newspapers.

Table 2 shows the radios', televisions' and the Internet's difference between the predicted values of newspapers with reality.

The error we have in the predicting work values from a percentage of 0.03 to 4.70, which means the work might be an acceptable one.

\subsection{Prediction of Communication Networks' Relationships}

Only consider that the development tendency of a particular kind of media itself. It might be applicable in a short term (for instance, 4 or 5 years), but must be a more considerable error in the long run. To solve this problem, the paper is going to use the pyramid model, which we've built in task 1, aiming at eliminating errors.

The media provides several general and specific functions. Generally speaking, the media provides information, interpretation, instructive, bonding, and diversion functions [2]. Besides, the media penetration rates have been organized to show three phases of a technology's spread: traction, maturity, and saturation [3]. The dark green color in the figure means the traction stage of the penetration rate, with the numerical value in it, which stands for the year when the utilization reaches $10 \%$; light green represents the maturity stage and the value inside means the year when the utilization reaches $45 \%$; the grey color means the saturation stage and the numerical value inside means the year when the utilization reaches $75 \%$.

Table 1. The comparison for newspapers (house).

\begin{tabular}{ccccccc}
\hline \multirow{2}{*}{ Media } & \multicolumn{5}{c}{2011} & \multicolumn{2}{c}{2012} \\
\cline { 2 - 6 } & Prediction & Reality & Error & Prediction & \multirow{2}{*}{ Reality } & \multirow{2}{*}{ Error } \\
\hline \multirow{2}{*}{ Newspapers } & $82,780,600$ & $83,280,000$ & $0.60 \%$ & $77,384,200$ & $80,160,000$ & $3.59 \%$ \\
\hline
\end{tabular}


Table 2. The comparison for radios, TVs and the Internet (person).

\begin{tabular}{|c|c|c|c|c|c|c|}
\hline \multirow{2}{*}{ Media } & \multicolumn{3}{|c|}{2011} & \multicolumn{3}{|c|}{2012} \\
\hline & Prediction & Reality & Error & Prediction & Reality & Error \\
\hline Radios & $67,174,300$ & $68,920,690$ & $2.50 \%$ & $66,594,600$ & $69,900,000$ & $-4.70 \%$ \\
\hline Televisions & $116,107,800$ & $114,700,000$ & $1.23 \%$ & $117,067,000$ & $116,500,000$ & $0.49 \%$ \\
\hline Internet & $249,727,700$ & $245,200,000$ & $1.84 \%$ & $257,192,300$ & $257,260,000$ & $-0.03 \%$ \\
\hline
\end{tabular}

Above all, the paper is going to explore the communication networks' relationships in a quantitative way.

We assume that the changes between 3 different stages are smooth straight lines, then we can simply distinguished that the difference of a particular media can be listed as follows:

$$
M_{n}{ }^{\prime}=\left\{\begin{array}{l}
c_{1}=\frac{10 \%}{\text { the traction year }} \\
c_{2}=\frac{45 \%-10 \%}{\text { the maturity year }} \\
c_{3}=\frac{75 \%-45 \%}{\text { the saturaton year }}
\end{array}\right.
$$

The influence of an advanced media to the elementary ones $I$ (year) in equation (1) can be expanded as follows:

$$
I_{n}=\sum_{i=n+1}^{\max } a_{n i} I_{i}
$$

$I_{i}$ means the specific advanced media which ranks higher than the pending one in the pyramid model; $a_{n i}$ represents ratio coefficient of the media.

Then Equation (1) can be expanded as

$$
M_{n}=f_{n}(\text { year })+\sum_{i=n+1}^{\max } a_{n i} I_{i}
$$

Equation (3) can be used to describe the relationships between different communication networks.

\subsection{Prediction of Capacities around the Year 2050}

To make a prediction of the communication networks' capacities around the year 2050, Equation (3) is needed. However, it's not enough. The consideration of population structure must be taken into account.

From the Media Dependency Theory, we could know that, the more a person relies on a kind of media, the more important this media it is to his daily life. Besides, the media may influence this person deeply. Meanwhile, this person will not change his alternative to another media easily.

When take the restraint of the media which comes later to the earlier one into account, the newly born babies may not choose to read newspapers anymore. We build acoefficient selection matrix. 


$$
B=\left[\begin{array}{lllll}
b_{1} & b_{2} & b_{3} & b_{4} & b_{5}
\end{array}\right]
$$

It aims at explaining the probability of a baby's choice. The value of each coefficient means the probability of a baby would choose that media at that time, and this may explain the change rate of media choosing of different age groups.

Then, we can list equations as follows:

$$
\left\{\begin{array}{c}
B_{0}=f_{n}(\text { year })+\sum_{i=n+1}^{\max } a_{n i} I_{i} \\
B_{n}=N_{n}+B_{n-1}-D_{n-1}
\end{array}\right.
$$

These equations help us explore the population structure's influence. The data we have come from Age and Sex Composition.

The prediction of capacities in 2050 is listed in Table 3.

A problem is that the total rate of the capacities is not equal to $100 \%$. The reason is that the source data we can get from the Internet overlaps each other, which means the people who may not only use one kind of media.

\subsection{Task 4: Introduction of EML Model}

A large percentage of people who took part in a recent research claimed that they prefer political news without a particular point of view than those with political perspectives.

Based on the theories of Mass Communication, the mass media can be regarded as a business opportunity, an educator, a watchdog or an entertainer. According to the study results of Petty and Sherman (who are psychologists), we built the elaboration likelihood model (ELM).

The two most important factors in the elaboration likelihood model are the abilities and motivation of the audiences. We assume that when the audiences receive the news, he or she would begin to digest the news. On account of the degree of information and the audience him or herself, the audience can have 2 ways to handle the news:

The first one is when the motivation and ability both are in a high level, the audiences prefer the centrums route. Besides, when one of the motivation or ability is in a low level, the audiences prefer the edge route.

Based on the ELM model, we defined the centrums route as an active way, which enables people to actively accept the information they received; on the

Table 3. The prediction of capacities in 2050.

\begin{tabular}{ccc}
\hline Media & Audience & Percentage \\
\hline Newspapers & $46,600,912$ & $10.62 \%$ \\
Radio & $56,610,340$ & $12.90 \%$ \\
Television & $184,695,897$ & $42.07 \%$ \\
The Internet & $396,702,606$ & $90.36 \%$ \\
Phone & $329,112,627$ & $74.97 \%$ \\
\hline
\end{tabular}


contrary, the edge route may be defined as a passive way which makes people passively accept the information they received.

The centrums route enables audiences to consciously study news provided by media, carefully analyze and summarize these news result in forming or changing their attitudes; the edge route means: Audiences will not consider the value of the news itself. Instead of doing do any logical reasoning, they intend to respond directly by the news according to practical situations, such as the reliability of information sources and universality of media.

With the centrums route, when it comes to publishing the news, the media can always change the interest and opinion of the public by choosing the most valuable information or an authoritative way. While it comes to the news which is not that important, the media often use hypodermic needle approach theory, bullet theory or cultivation theory, taking on as if by osmosis their likes and dislikes.

\subsection{Factors Weighting}

Based on the ELM model we've built in task 4, this paper is going to describe how the specific factors (the value of information, people's initial opinions, form or source, and the strength of topology) could be used in a qualitative equation.

$$
\left.\left.Z=[A \cdot(\text { value })+B \text { (initial opinion })+C(\text { form, source })_{\max }\right] \times D \text { (strength }\right)
$$

$Z$ in this equation stands for the influence of public opinions; $A, B, C$ and $D$ are the variation coefficients of each factor, ranging from 0 to 1 .

\section{The Information Value}

Based on the view of information adoption model showed we regard the course of information influencing people's choice-making as information adoption course. The more valuable the information is, the more potential it is for information to influence people by the centrums route; otherwise, it is called the edge route.

There're many expressing forms of news, such as words, audios, images and videos. Different expressing forms may lead to different effects. Then, what are these effects? It is the decision people made about the authenticity of the information. People tend to believe something they saw rather than something they heard. Based on the view of information adoption model showed in Figure 1, we regard the course of information influencing people's choice-making as

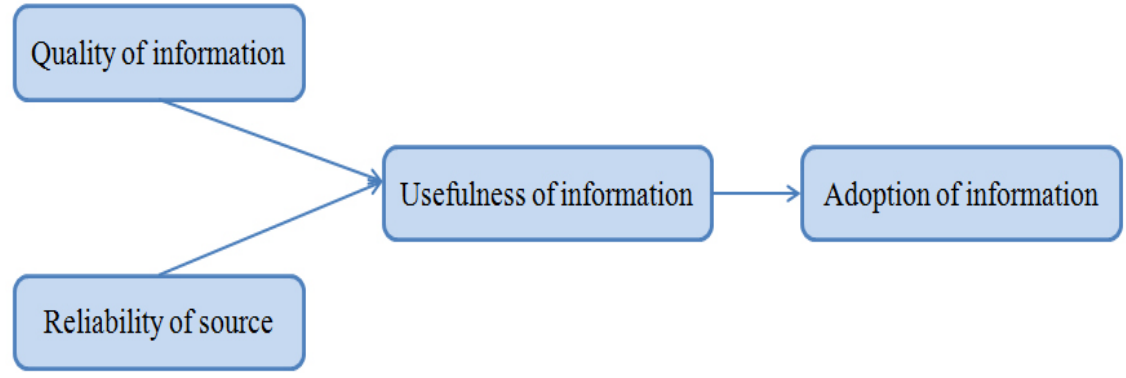

Figure 1. The information adoption model. 
information adoption course. The more valuable the information is, the more potential it is for information to influence people by the centrums route; otherwise, it is called the edge route. Therefore, people are more likely to believe: first, the video news; second, images and audios; third, words. At this moment, the source of information and the authority of media are not taken into consideration. The form levels of news are as follows: video, 4; image, 3; audio, 2; word, 1.

And also, the authority of news source may influence the degree people accept the information. People tend to agree with the authorities. For example, Osama bin Laden has been announced dead for 6 times, however, only when Obama announced his death did the public believed this. At the same time, the information authoritative media released make it easier for people to accept. For example, the news NBC released is more persuasive than the news other media released. Considering these two points, we quantify the authority of information source. It includes four levels, ranging from 1 to 4.

During the course of solving the equation, we comprehensively considered the authority of news form and source. The maximum value of these two levels was selected. The larger the maximum value is, the delivering way of information gets closer to the centrums route.

\section{Conclusions}

The first model is for the information flows through the media channel become news, meanwhile, the media play an important role in this process that determine the direction of the flow of the information. The second model considers that the media which appeared later could restrain the media appeared early. The third considers that only through the centrums route, people could change their opinion firmly, and also have chance to know about the value of information. If else, people might go through edge route to judge, it creates chance for the topology or strength of the information network to influence people's opinion. The fourth model considers that the higher value the information has, the higher possibility it can be adopted by the society's network.

This model can accurately predict information communication situation for today, communication networks' relationships and capacities around the year 2050 , for the reason that the main influence factors are fully taken into consideration. The concise form and interdisciplinary analyses make our model multipurpose for use.

\section{References}

[1] The Relationship between Information and News. http://www.docin.com/p-392380959.html

[2] Sussman, S.W. and Siegal, W.S. (2003) Informational Influence in Organizations: An Integrated Approach to Knowledge Adoption. Information Systems Research, 14, 47-65. https://doi.org/10.1287/isre.14.1.47.14767

[3] New York County Selection Map. http://www.nygenweb.net/county.htm 